Research Article

\title{
Stabilization of Expansive Soil with Polyvinyl Alcohol and Potassium Carbonate
}

\author{
Fuhai Zhang, ${ }^{1}$ Lei Zhang $\mathbb{D}^{2}{ }^{2}$ and Wangxi Hong ${ }^{3}$ \\ ${ }^{1}$ Key Laboratory of Ministry of Education for Geomechanics and Embankment Engineering, Geotechnical Research Institute, \\ Hohai University, Nanjing 210098, China \\ ${ }^{2}$ School of Civil and Construction Engineering, Oregon State University, 101 Kearney Hall, Corvallis, OR 97331, USA \\ ${ }^{3}$ Jiangsu Changjiang Mechanization Foundation Engineering Co., Ltd., Nanjing, China \\ Correspondence should be addressed to Lei Zhang; zhanglei@oregonstate.edu
}

Received 6 August 2019; Revised 21 October 2019; Accepted 31 October 2019; Published 14 November 2019

Academic Editor: Sanjay Nimbalkar

Copyright (c) 2019 Fuhai Zhang et al. This is an open access article distributed under the Creative Commons Attribution License, which permits unrestricted use, distribution, and reproduction in any medium, provided the original work is properly cited.

\begin{abstract}
Expansive soils have great volume change potentials with water content changes, which is problematic to facilities. Great efforts have been spent on finding proper methods to stabilize expansive soils, but these stabilizers all had limitations. The Polyvinyl alcohol (PVA) and $\mathrm{K}_{2} \mathrm{CO}_{3}$ combination was proposed in this paper. Free swell tests, oedometric tests, unconfined compression tests, and direct shear tests were performed to investigate the effectiveness of the PVA and $\mathrm{K}_{2} \mathrm{CO}_{3}$ combination to control the volume change and increase the soil strength. Microstructures of the natural expansive soil and the stabilized soil were also studied with SEM photos. SEM photos showed a homogenous and dense microstructure after stabilization. In addition, a laboratory soil column model was built to study the ability of this stabilizer combination to stabilize expansive soils by directly spraying the solution on the ground surface. All these test results show that the combination of PVA and $\mathrm{K}_{2} \mathrm{CO}_{3}$ is able to effectively stabilize the natural expansive soil and increase the shear strength. It is possible to directly spray the stabilizer solution on the soil surface to form a relatively thick layer of the stabilized expansive soil.
\end{abstract}

\section{Introduction}

Expansive soils have large volume change potentials with water content changes, causing problems such as slope failures (e.g., [1]) and foundation damages (e.g., [2]), especially when there are wetting-drying cycles (e.g., [3]). Great efforts by previous researchers have been done on stabilizing expansive soils and increasing their strengths. Most popular methods to stabilize expansive soils are to mix natural expansive soils with different types of stabilizers. Researchers have been trying to reinforce expansive soils with natural plant fibers such as coir waste by Jayasree et al. [4]; bagasse fiber by Dang et al. [5], and jute fiber by Wang et al. [6]. Manufactured fiber products were used more often (e.g., [7-9]). Recycled fibers such as carpet waste fibers (e.g., $[10,11])$ were also used as expansive soil stabilizers. In addition, Expanded Polystyrene (EPS) geofoam was used as an expansive soil stabilizer by Ikizler et al. [12].
Stabilizers involving chemical reactions with expansive soils used were more popular. Lime was very often used as an expansive soil stabilizer (e.g. $[13,14])$. Cements were also commonly used as expansive soil stabilizers (e.g., $[15,16])$. However, cements are typically very expensive, so affordable stabilizers are needed in practice. Fly ashes typically extracted from the furnace flue fired with coal can also provide sufficient cation exchanges when they are mixed with expansive soils, effectively stabilizing expansive soils (e.g., [17-19]). Furnace slag is another type of stabilizer (e.g., $[20,21])$. There are also other rarely used stabilizers such as sulphonated oil by Soltani et al. [22].

However, these stabilizers are nonsoluble or have low solubility to water. Due to complicated site conditions in the field, other than the soil filling projects, it is hard to directly mix field soils with stabilizers as that in the laboratory. Therefore, it is necessary to find a new stabilizer with high solubility to water, and possibly, this new stabilizer solution 
could be directly sprayed to the ground surface to stabilize the expansive soil in a considerable depth. $\mathrm{K}^{+}$can be considered as a great swelling inhibitor because of the lowest hydration energy [23], but it works well only if the soil has swelled with water content increase. Polyvinyl alcohol (PVA) is soluble to water and it reacts with the ions on the crystals, forming complicated and relatively stable compound. Therefore, in order to combine the advantages of these two types of stabilizers, PVA and potassium carbonate $\left(\mathrm{K}_{2} \mathrm{CO}_{3}\right)$ will be mixed and used together in this work. Yu et al. [24] proposed a mixture of PVA and $\mathrm{KCl}$ to stabilize expansive soils, but they only performed free swell tests, particle size distribution tests, and disintegration tests. However, more important parameters such as oedometric swelling, shear strength, and dryingwetting cyclic stability were not studied, but they will be investigated in this paper. In addition, the advantage of using $\mathrm{K}_{2} \mathrm{CO}_{3}$ instead of $\mathrm{KCl}$ is that $\mathrm{CO}_{3}^{2-}$ can easily react with $\mathrm{H}_{2} \mathrm{O}$, producing $\mathrm{HCO}_{3}^{-}$and $\mathrm{OH}^{-}$which will form weak alkaline solution. In natural expansive soils, there are often ions of $\mathrm{Ca}$, $\mathrm{Si}$, and $\mathrm{Al}$, and these ions will react and generate gelatinous compound in the weak alkaline environment, which will finally increase the soil strength and reduce the swelling potential. Microscopic parameters of stabilized soils were studied with SEM by previous researchers (e.g., $[25,26])$, and will also be studied in this paper. In addition, the effectiveness of stabilizing expansive soils by spraying this stabilizer mixture to site soil surfaces will be studied with a soil column model in the laboratory.

\section{Experimental Program}

2.1. Free Swell Tests. The free swell potential is a very important property of expansive soils. Three groups of free swell tests, firstly proposed by Holtz and Gibbs [27], were performed following the Chinese standard [28] with floating sample rings. In group one, expansive soil samples with the initial moisture content of $20 \%$, the dry natural density of $1.6 \mathrm{~g} / \mathrm{cm}^{3}$, and the maximum dry density of $1.871 \mathrm{~g} / \mathrm{cm}^{3}$ were only stabilized by $\mathrm{K}_{2} \mathrm{CO}_{3}$ by weight of $1 \%, 2 \%, 3 \%, 4 \%, 5 \%$, and $6 \%$ of the dry expansive soil, respectively; in group two, soil samples were only mixed with PVA by weight of $0.05 \%$, $0.1 \%, 0.2 \%, 0.3 \%, 0.4 \%, 0.5 \%$, and $0.6 \%$ of the dry soil; and in group three, soil samples were improved with the mixtures with $\mathrm{K}_{2} \mathrm{CO}_{3}$ of $3 \%$ of the dry expansive soil and PVA amounts of $0.1 \%, 0.2 \%, 0.3 \%, 0.4 \%, 0.5 \%$, and $0.6 \%$ of the dry expansive soil.

2.2. Oedometric Swell Tests. Oedometric swell tests were conducted with vertical swelling only from the top of samples. Devices used in oedometric swell tests included the oedometer, the ring-sampler with the diameter of $61.8 \mathrm{~mm}$ and the height of $20 \mathrm{~mm}$, and the displacement gauge with the maximum reading of $10 \mathrm{~mm} . \mathrm{K}_{2} \mathrm{CO}_{3}$ powders having weights of $1 \%, 3 \%$, and $5 \%$ of the dry expansive soil were prepared, and PVA powders having weights of $0.1 \%, 0.3 \%$, and $0.5 \%$ of the dry expansive soil were prepared. Then, these powders were mixed together and dissolved into water. 16 solutions were prepared with different ratios of $\mathrm{K}_{2} \mathrm{CO}_{3}$ and PVA. Finally, these 16 solutions were mixed with expansive soil samples, and then cured for 24 hours with the water content of about $20 \%$ which was the minimum average water content in dry seasons, and the samples were collected from the ground surface to the depth of $2.5 \mathrm{~m}$ near the highway construction field. Therefore, the mass of the mixture $\left(m_{s}\right)$ needed in the ring samples was calculated with the following equation:

$$
m_{s}=\rho_{d} \cdot v \cdot(1+\omega)
$$

where $\rho_{d}$ is the dry density of the ring samples; $v$ is the sample volume; and $\omega$ is the water content. In order to fill the ring-samplers with the right amounts of soil samples, two rings were stacked up on a steel plate with smooth surface. Next, the soil mixture was poured into the ring-stack with a cylindrical metal plate on top with the same diameter as that of the ring-stack. Finally, a hydraulic stripping machine was used to push the cylindrical metal plate until its top surface was on the same level as the top of the top ring-sampler.

In the loaded oedometric swell tests, samples were immediately put onto the oedometer and loaded with $50 \mathrm{kPa}$ from the top. Then, when the vertical strain rate was smaller than $0.01 \mathrm{~mm}$ per hour, distilled water was poured into the sample container on the oedometer with the water surface $5 \mathrm{~mm}$ higher than the sample top surface. The sample height was recorded every two hours until the difference of two adjacent readings was smaller than $0.01 \mathrm{~mm}$.

In the free oedometric swell tests, ring samples were immediately put onto the consolidometer and the sample container was filled with distilled water, and the water surface was set to $5 \mathrm{~mm}$ higher than the sample top surface. The sample height was recorded every two hours until the swelling strain rate was smaller than $0.01 \mathrm{~mm}$ every 6 hours.

2.3. Unconfined Compression Tests. Because stabilized expansive soils will be used in the field construction projects, compression strength is always the most important property. Unconfined strength tests were performed to determine compression strengths of samples with different curing periods. The natural expansive soil used in tests had the dry natural density of $1.6 \mathrm{~g} / \mathrm{cm}^{3}$ and the maximum dry density of $1.871 \mathrm{~g} / \mathrm{cm}^{3}$. The samples were mixed and stabilized with PVA with the weight of $0.5 \%$ of the dry natural expansive soil and $\mathrm{K}_{2} \mathrm{CO}_{3}$ with the weight of $3 \%$ of the dry natural expansive soil. The stabilized samples and natural expansive soils were sealed in the same environment for 24 hours with the water content of approximately $20 \%$. Then, 16 samples of stabilized soil and 16 samples of natural expansive soil were prepared by a hydraulic stripping machine with the diameter of $5 \mathrm{~cm}$ and the height of $5 \mathrm{~cm}$. These samples were cured in wet sand for 7 days, 14 days, 21 days, and 28 days, respectively. Finally, they were compressed with the axial strain rate of $0.4 \mathrm{~mm} / \mathrm{min}$ without any lateral constrains, making sure that they failed within 7-14 min.

2.4. Effects of Cyclic Drying-Wetting. The drying-wetting cycles simulate changes of water content in the field with 
seasonal weather changes. The stabilized soil samples had PVA with the weight of $0.5 \%$ of the dry natural expansive soil and $\mathrm{K}_{2} \mathrm{CO}_{3}$ with the weight of $3 \%$ of the dry natural expansive soil. The samples were prepared with ring-samplers with the diameter of $61.8 \mathrm{~mm}$ and the height of $20 \mathrm{~mm}$. In the tests, the water contents were varying in the range between 19\% and $25 \%$, simulating the partial drying and partial wetting. After each drying-wetting cycle, photos of the samples were taken and the sizes of cracks were measured with a digital caliper.

The undrained shear strengths of the samples before drying-wetting cycles and after 2 and 4 drying-wetting cycles were tested with direct shear tests. During shearing, the vertical pressures were set to $100 \mathrm{kPa}, 200 \mathrm{kPa}, 300 \mathrm{kPa}$, and $400 \mathrm{kPa}$. Then, samples were sheared with the strain rate of $1.2 \mathrm{~mm} / \mathrm{min}$ and without water drainage, so they could fail within 3-5 mins.

2.5. SEM Tests. A soil sample was scanned with the scanning electron microscopy (SEM). The SEM device model was XL30 which was produced by the EDAX company. The soil sample had PVA with the weight of $0.5 \%$ of the dry natural expansive soil and $\mathrm{K}_{2} \mathrm{CO}_{3}$ with the weight of $3 \%$ of the dry natural expansive soil. The soil sample was cured for 7 days, and then dried and cut into small pieces with one smooth side sticking to the metal plate.

2.6. Infiltration Test. In the infiltration test, a soil column was built and shown in Figure 1. The soil column container had the height of $1 \mathrm{~m}$, the length of $0.19 \mathrm{~m}$, and the width of $0.13 \mathrm{~m}$ with cross cuttings at the heights of $10 \mathrm{~cm}, 40 \mathrm{~cm}$, and $70 \mathrm{~cm}$ from the bottom to easily collect soil samples at these three heights. The natural expansive soil passed a sieve with $2 \mathrm{~mm}$ openings, and then was cured for 24 hours with the water content of about $19 \%$. The natural expansive soil had the dry natural density of $1.6 \mathrm{~g} / \mathrm{cm}^{3}$ and the maximum dry density of $1.871 \mathrm{~g} / \mathrm{cm}^{3} .33 .6 \mathrm{~kg}$ soil was filled into the container with the degree of compaction of $85.5 \%$. The PVA stabilizer solution was prepared with PVA with the weight of $0.5 \%$ of the dry natural expansive soil, and the $\mathrm{K}_{2} \mathrm{CO}_{3}$ stabilizer solution was prepared with the weight of $3 \%$ of the dry natural expansive soil. $2000 \mathrm{~mL}$ of the $\mathrm{K}_{2} \mathrm{CO}_{3}$ stabilizer solution was sprayed onto the soil surface at once. Then, $723 \mathrm{~mL}$ of the PVA stabilizer solution was sprayed onto the top surface of the soil column every day for seven days.

\section{Test Results and Discussion}

3.1. Free Swell Test. Free swell tests were performed to study the soil swelling potential. Free swell index (FSI) was calculated with the following equation:

$$
\mathrm{FSI}=\frac{V_{w}-V_{0}}{V_{0}} \times 100,
$$

where $V_{w}$ is the volume of soil after swelling and $V_{0}$ is the volume of dry soil. The FSI values in the three groups of tests are plotted in Figure 2. It can be seen that with the increase of stabilizer amounts, FSI values decrease for all the three groups of tests. Referring to the Chinese standard [28], if the FSI value is smaller than $40 \%$, the soil will not be considered as expansive soil any more. In Figure 2(a), the amount of $\mathrm{K}_{2} \mathrm{CO}_{3}$ has to be larger than $5 \%$ of the dry expansive soil to reduce the FSI value to $39.5 \%$ which is smaller than $40 \%$. In Figure 2(b), all values of FSI are larger than 40\%. In Figure 2(c), it shows that the FSI value is reducing faster than those in Figures 2(a) and 2(b), and when the PVA amount is less than $0.5 \%$, FSI is reduced to $33 \%$ which is even reduced by $45.5 \%$ of that with the same amount of PVA in Figure 2(b).

3.2. Oedometric Swell Tests. Free oedometric swell tests were conducted with free swell from the top, and the lateral swell of the samples was not allowed. In the loaded oedometric swell tests, the lateral swell was also prohibited, but $50 \mathrm{kPa}$ vertical load was added to the top of the sample. In order to quantify the swell behavior, oedometric swell index (OSI) was calculated as follows:

$$
\text { OSI }=\frac{Z-Z_{0}}{h_{0}} \times 100,
$$

where $Z$ is the current displacement gauge reading; $Z_{0}$ is the initial displacement gauge reading; and $h_{0}$ is the initial height of the sample. When the swell stopped, the OSI values for samples with different amounts of PVA and $\mathrm{K}_{2} \mathrm{CO}_{3}$ are shown in Figure 3. It shows that the OSI values in the free oedometric swell tests were so much larger than those in the $50 \mathrm{kPa}$ loaded oedometric swell tests. It also shows that the increasing amount of PVA and $\mathrm{K}_{2} \mathrm{CO}_{3}$ effectively decreased the amount of swell in both types of oedometric swell tests, but with the same amount of PVA, the decrease of OSI values by the increase of $\mathrm{K}_{2} \mathrm{CO}_{3}$ amount was more significant than that by the increase of the PVA amount with the same amount of $\mathrm{K}_{2} \mathrm{CO}_{3}$. It can be concluded that, with sufficient amount of PVA and $\mathrm{K}_{2} \mathrm{CO}_{3}$, the oedometric swell could be controlled to a reasonable small amount.

3.3. Unconfined Compression Tests. In order to investigate the effect of PVA and $\mathrm{K}_{2} \mathrm{CO}_{3}$ on the strengths of samples, unconfined compression tests were performed. The photos of the samples before and after tests are shown in Figure 4. It is clear that with the same length of cure period, the samples stabilized by PVA and $\mathrm{K}_{2} \mathrm{CO}_{3}$ had much smaller bulging after tests than those samples with only natural expansive soil, indicating the effectiveness of the stabilizers to increase the soil strength. For samples with only natural expansive soil, there was even small bulging before compression, which was not observed in the samples with the stabilized soil.

To quantify the effect of PVA and $\mathrm{K}_{2} \mathrm{CO}_{3}$ on sample strengths, the unconfined compression strengths versus different curing period are plotted in Figure 5. It confirms that the samples stabilized by PVA and $\mathrm{K}_{2} \mathrm{CO}_{3}$ had higher values of unconfined compression strengths. With the increase of curing period length, the unconfined compression strength values for stabilized soil samples were increasing, but the unconfined compression strength values for natural expansive soil samples were almost constant with different 


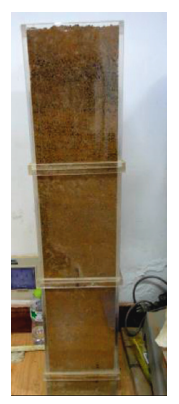

(a)

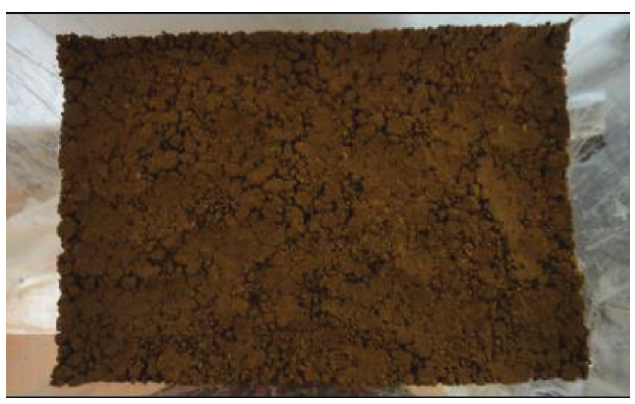

(b)

Figure 1: Photos of the soil column: (a) side view of the soil column; (b) plan view from the top of the soil column.

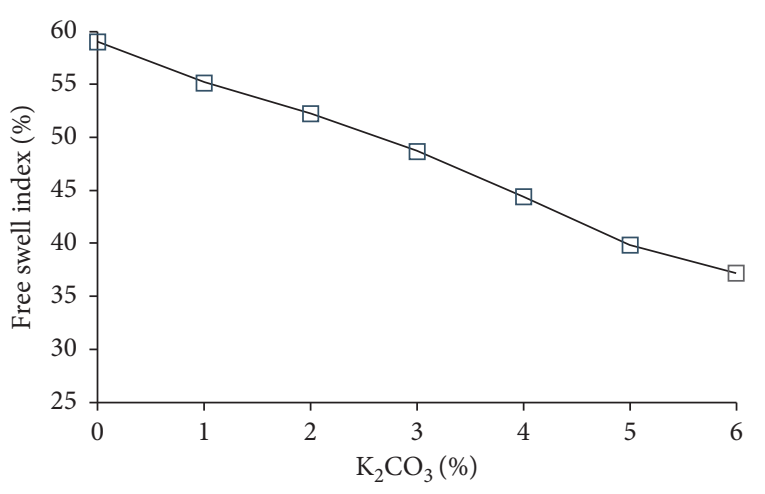

(a)

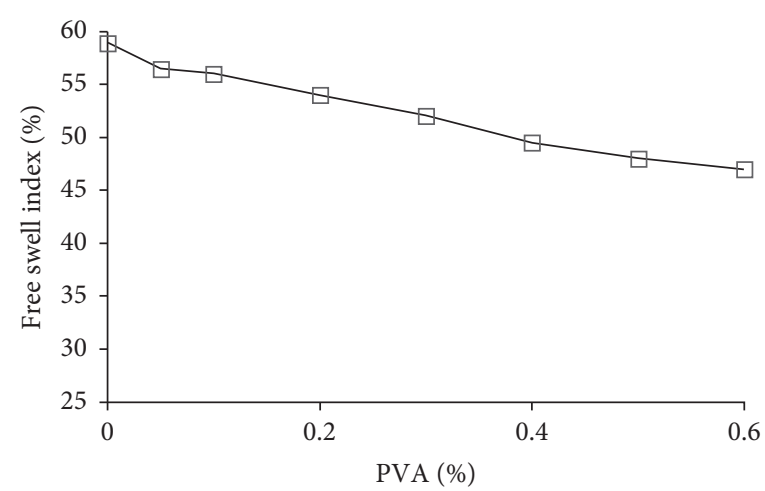

(b)

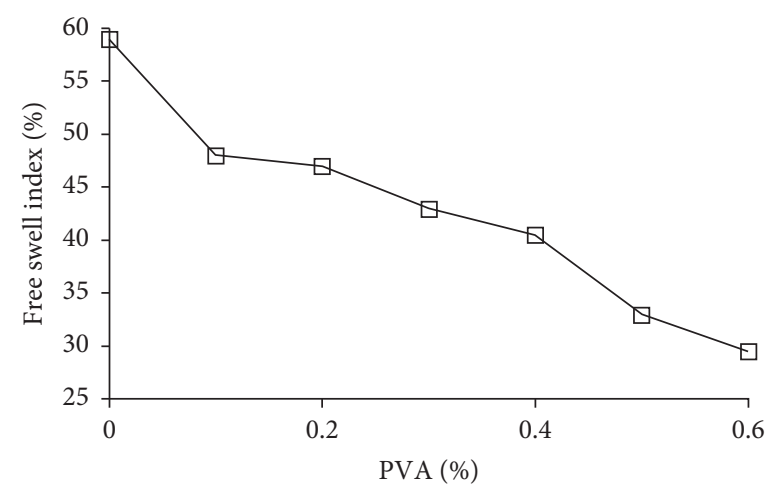

(c)

Figure 2: The free swell index values for samples with: (a) $\mathrm{K}_{2} \mathrm{CO}_{3}$ only; (b) PVA only; (c) $3 \%$ of $\mathrm{K}_{2} \mathrm{CO}_{3}$ and different amounts of PVA.

curing period lengths because natural expansive soil samples did not have any changes during the curing periods.

3.4. Effects of Cyclic Drying-Wetting. The majority of strength in expansive soil is from matric suction which is directly related to the water content [29]. Soil strength decreases with the decrease of matric suction caused by the water content increase. When the water content decreases, matric suction will increase, and soil will shrink and crack. Once there are cracks in soil body, water may easily infiltrate deeply, which will further decrease the soil strength. Thus, it is necessary to thoroughly investigate the effect of drying-wetting cycles on soil strength, and it is important to study the ability of stabilizers to reduce cracking. Figure 6 provides photos of the natural expansive soil samples after different cycles of drying-wetting. After 9 cycles, a large crack showed up going through the sample body. Figure 7 shows photos of the stabilized soil samples after different cycles of drying-wetting. Obviously, there are no through-type cracks even after 31 cycles of drying-wetting. The integrity of the sample was almost not changing after 31 cycles of drying-wetting because the samples were stabilized, and there was little volume change during drying-wetting cycles.

To quantify the effect of drying-wetting cycles on the strengths of both natural expansive soil and stabilized soil samples, direct shear tests were performed for samples 


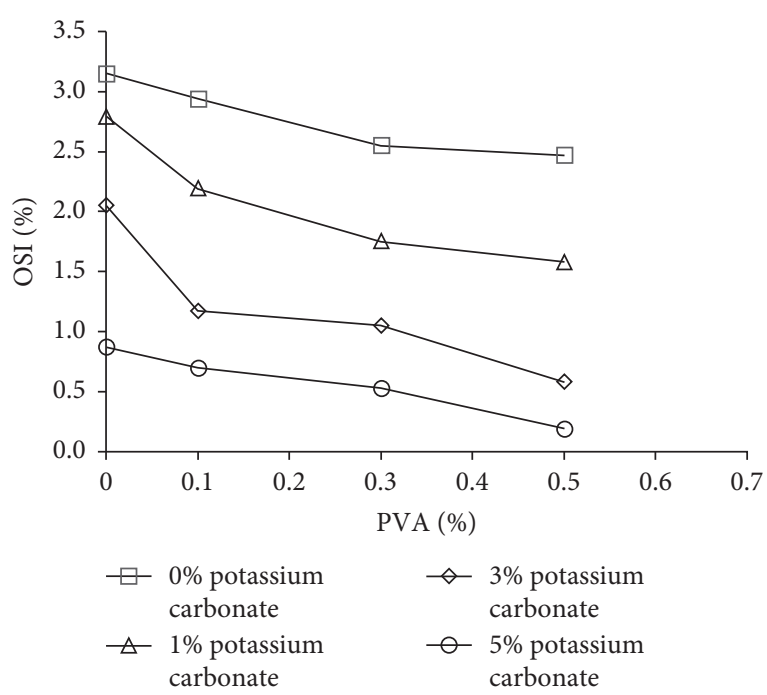

(a)

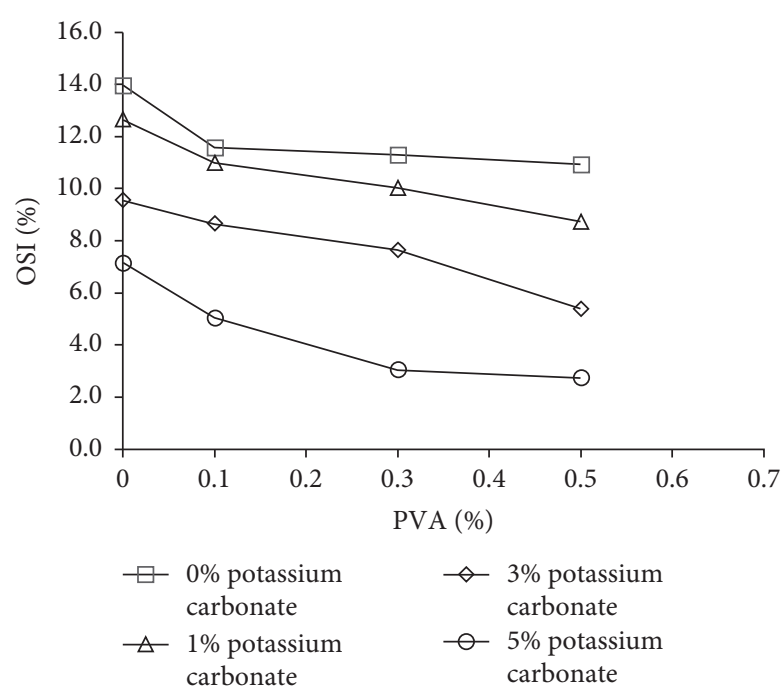

(b)

FIgURE 3: Oedometric swell test results (a) with a $50 \mathrm{kPa}$ vertical load; (b) without vertical load.
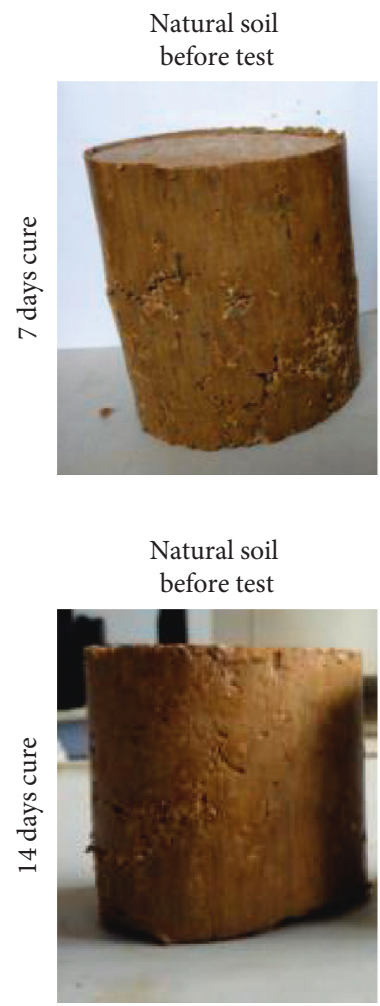

Natural soil after test

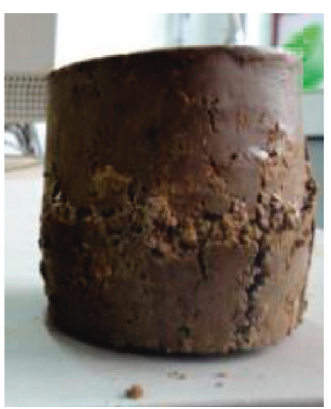

(a)

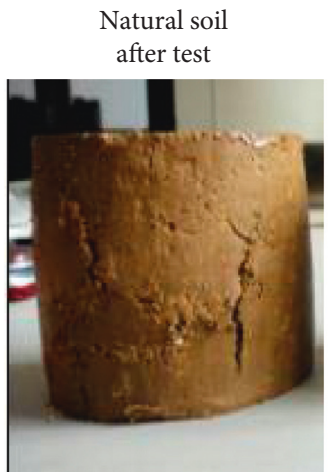

Stabilized soil before test

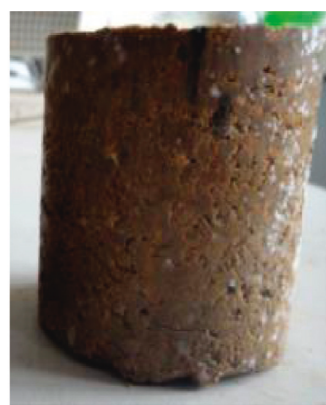

Stabilized soil

before test

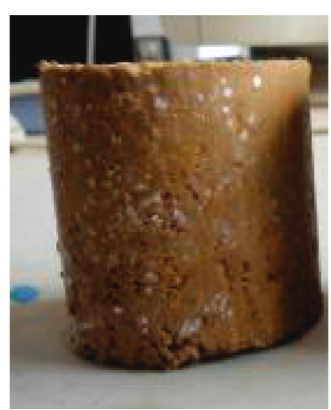

(b)
Stabilized soil after test

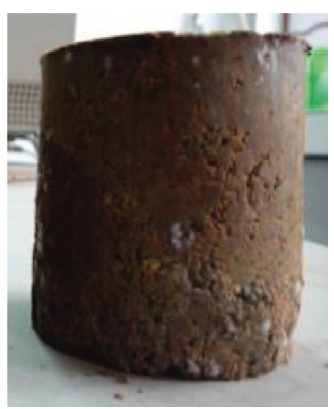

Stabilized soil after test

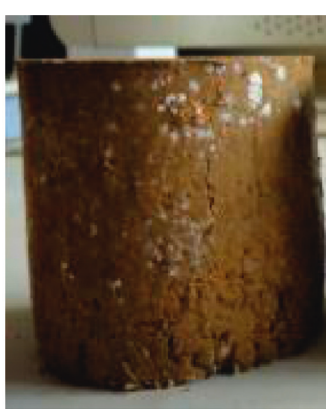

FIgUre 4: Continued. 

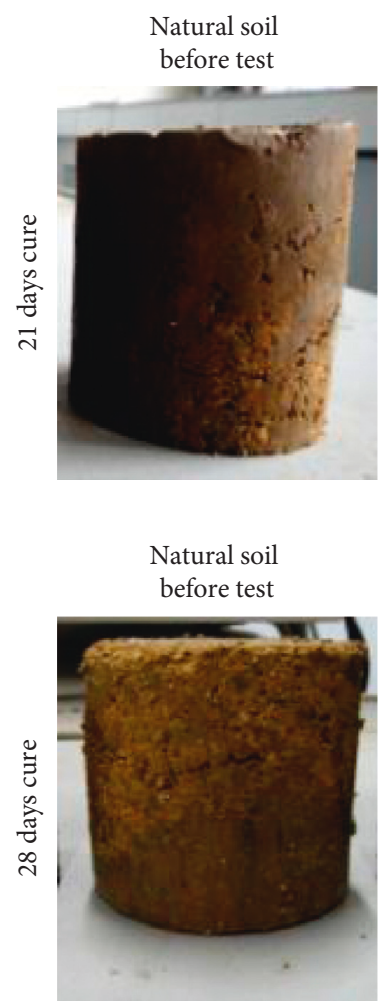

(c)
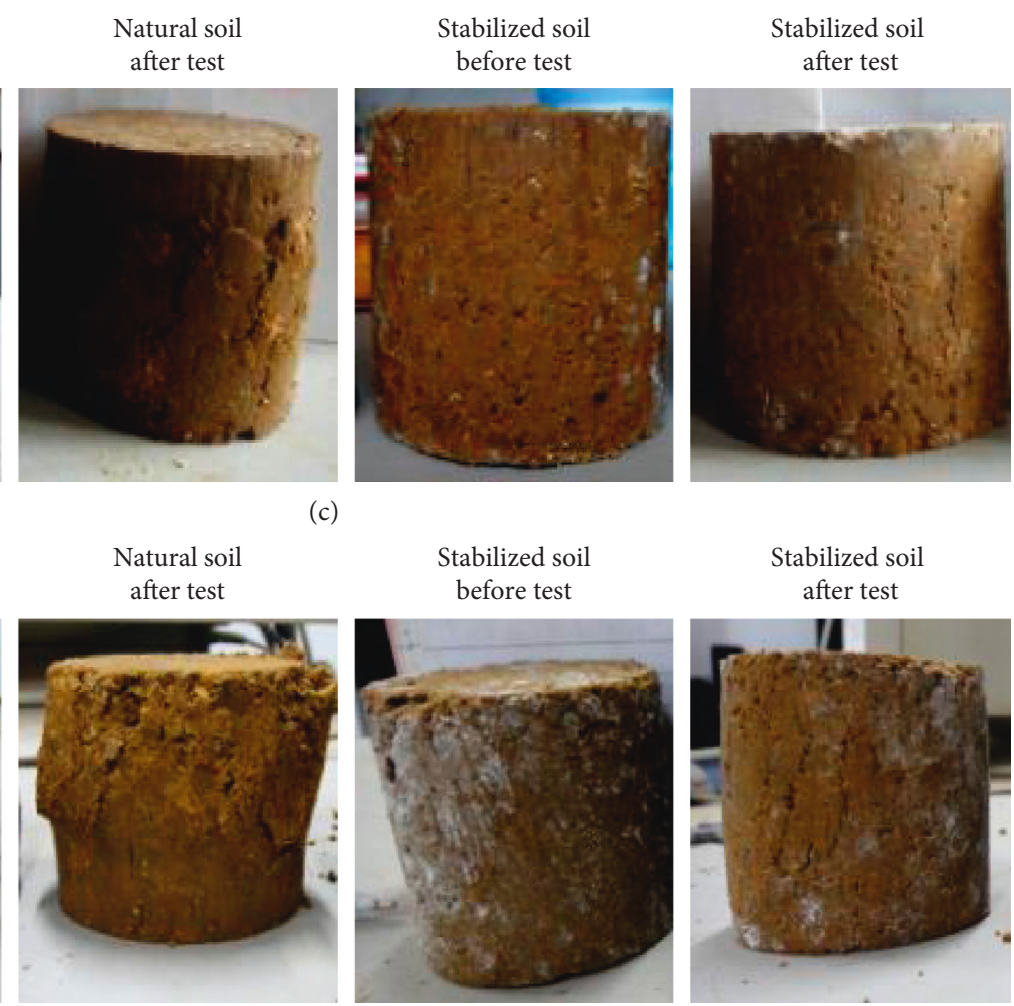

Stabilized soil before test
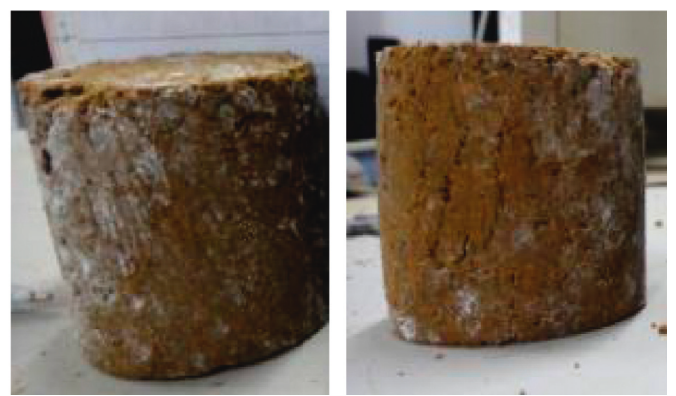

(d)

Figure 4: Photos of the samples before and after the unconfined compression tests.

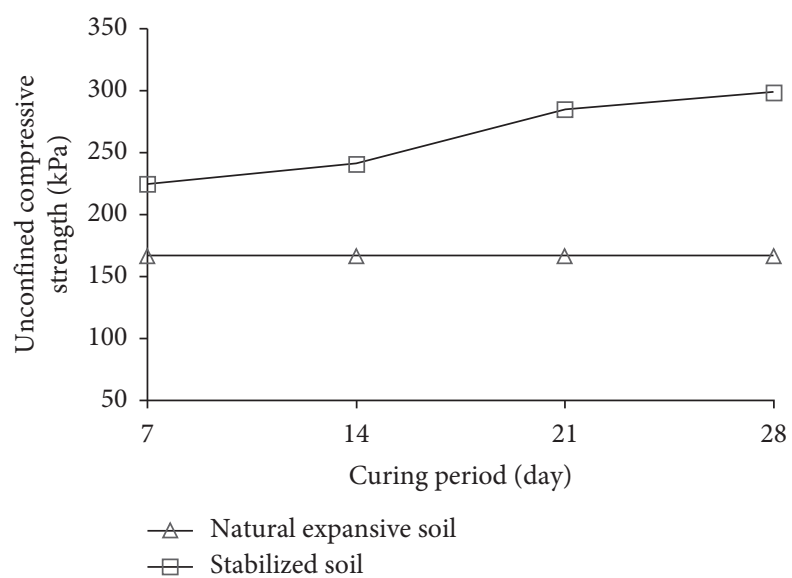

FIGURE 5: Unconfined compression strengths for samples with different curing periods.

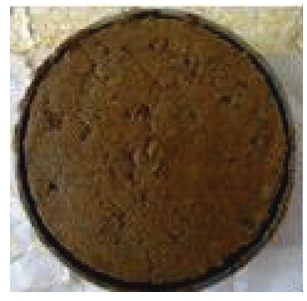

(a)

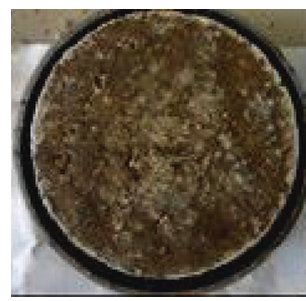

(b)

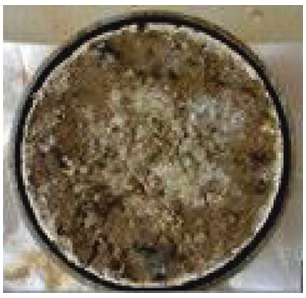

(c)

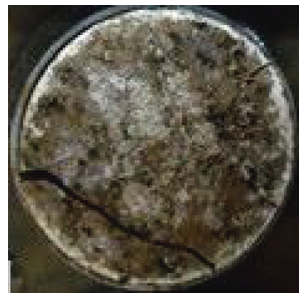

(d)

Figure 6: Photos of cracks on natural expansive soil samples with different numbers of drying-wetting cycles. (a) 1 cycle. (b) 5 cycles. (c) 8 cycles. (d) 9 cycles. 


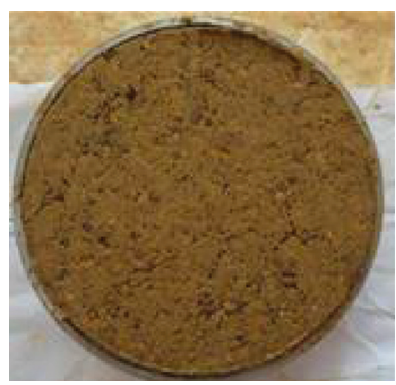

(a)

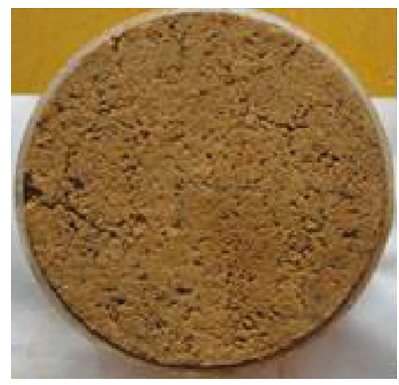

(d)

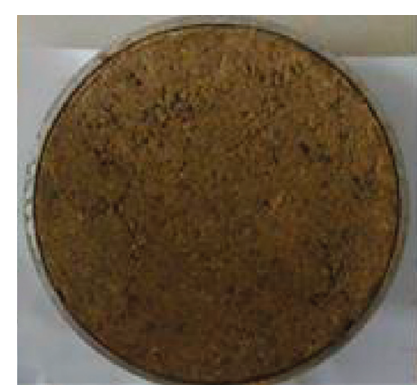

(b)

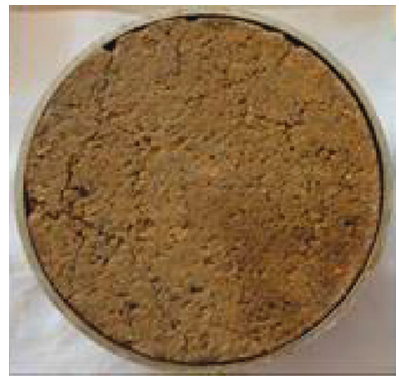

(e)

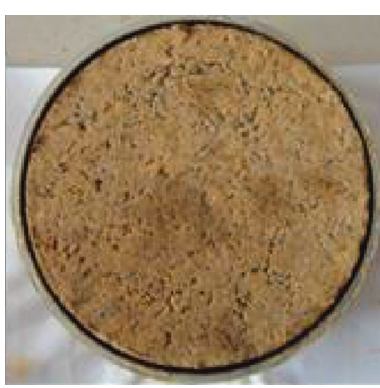

(c)

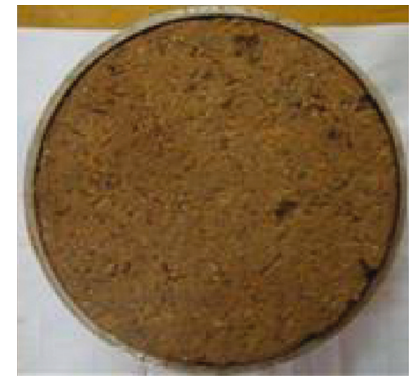

(f)

Figure 7: Photos of cracks on stabilized soil samples with different numbers of drying-wetting cycles. (a) 1 cycle. (b) 7 cycles. (c) 13 cycles. (d) 19 cycles. (e) 25 cycles. (f) 31 cycles.

before and after 2 cycles and 4 cycles of drying-wetting. Test results are shown in Figure 8. It can be seen that with the increase of vertical pressures, shear strengths for all the samples increased. The shear strengths of stabilized soil samples were larger than those of natural expansive soil samples because stabilizers reacted with the ions on the crystals, forming complicated and relatively stable compound. More importantly, for stabilized soil samples, with the increase of the drying-wetting cycles, the shear strength decreases were very limited because the stabilized samples had smaller volume changes and subsequently smaller reducing of shear strength. However, for natural expansive soil samples, the shear strength decreases were very significant.

Volume change during drying-wetting cycles is also a very important property to investigate. Figure 9 shows the vertical axial strain changes with the increase of the number of drying-wetting cycles. In Figure 9(a), the stabilized soil sample exhibited swelling-shrinking cycles with the cycles of drying-wetting, and the swelling-shrinking behavior was around a constant axial strain-4\%. In Figure 9(b), the natural expansive soil sample also showed swelling-shrinking cycles, but the average values of the axial strain were increasing with the increase of the number of drying-wetting cycles. Therefore, it can be concluded that the soil stabilizer was able to well control the axial deformation even if there were many numbers of drying-wetting cycles.

3.5. SEM Tests. The microstructure of the natural expansive soil and the stabilized expansive soil is directly related to the macroscopic swelling potential. Therefore, the scanning electron microscopy (SEM) was used to take photos of the soil microstructures shown in Figure 10. The soil particle

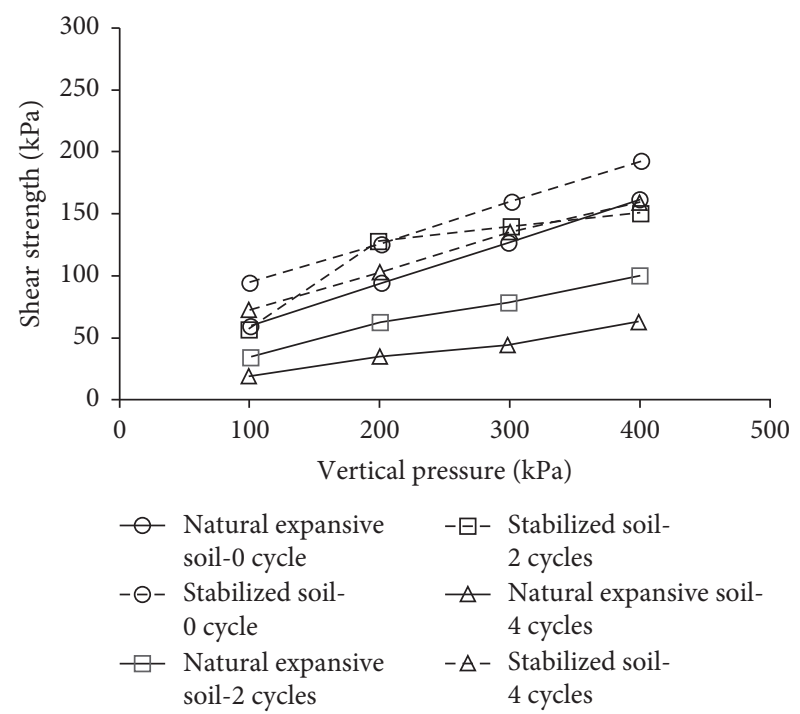

FIGURE 8: Direct shear strengths for samples with cycles of dryingwetting.

photos were taken at three scales: $100 \mu \mathrm{m}, 20 \mu \mathrm{m}$, and $10 \mu \mathrm{m}$. It shows that blocks of clay particles with the size of about $5 \sim 10 \mu \mathrm{m}$ spread out without any directionality. In the natural expansive soil, particles showed up as individual surface-flat blocks, loosely with large voids between particles. However, in the stabilized soil, clay particles were embedded into the PVA colloid. The soil was homogenous and very dense without large voids, which interpreted the increased soil strength from the microscale view of point. It can be concluded that the soil microstructure was completely changed by the stabilizer. 


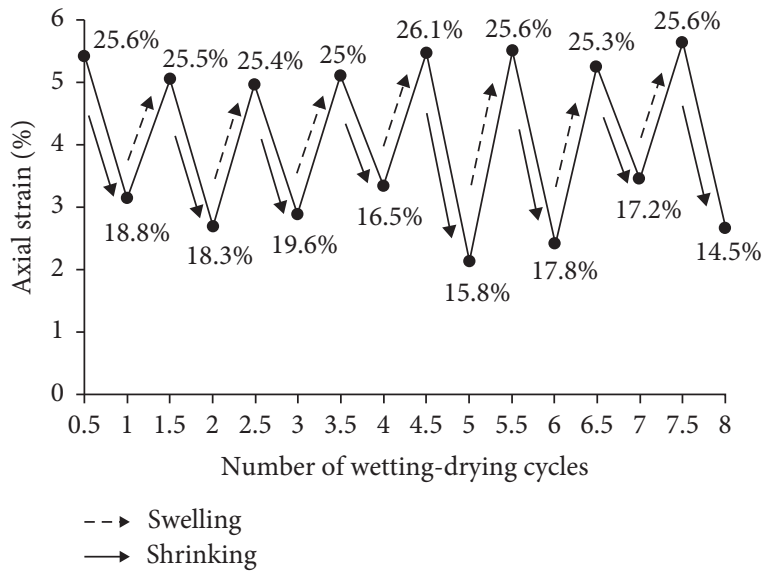

(a)

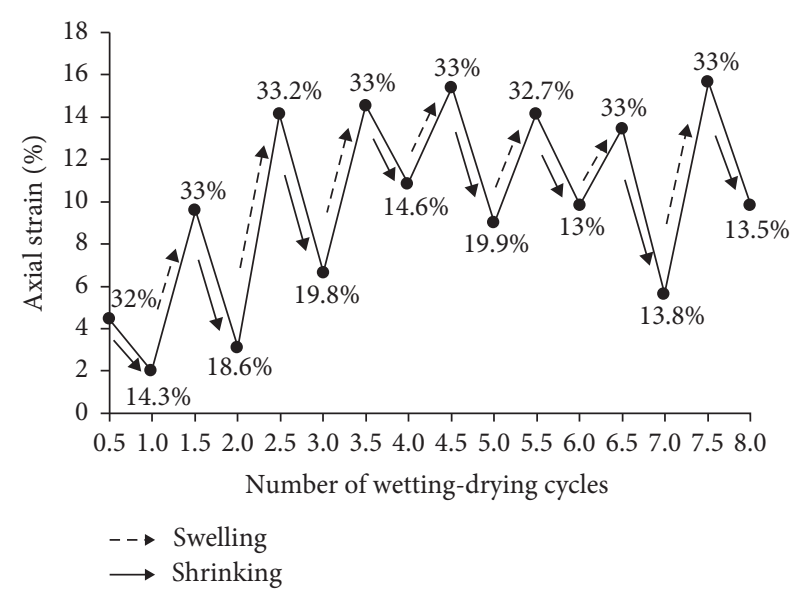

(b)

FIGURE 9: Axial deformations during swelling-shrinking cycles: (a) the stabilized soil sample; (b) the natural expansive soil sample.
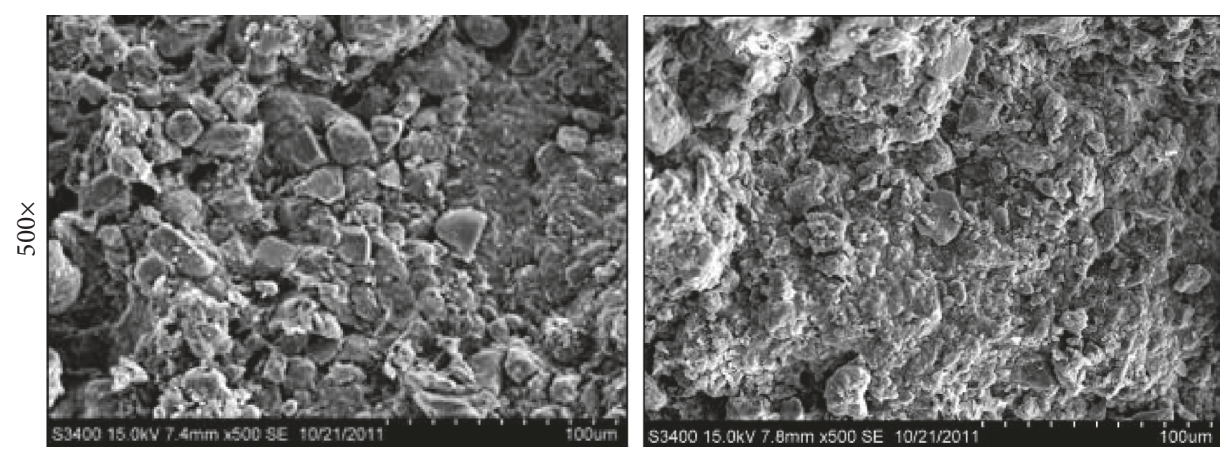

(a)
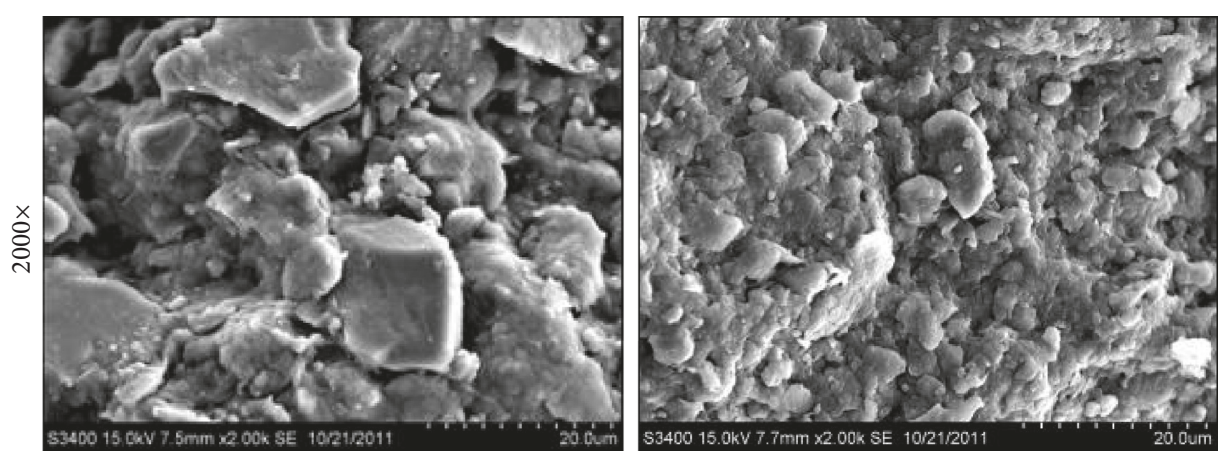

(b)
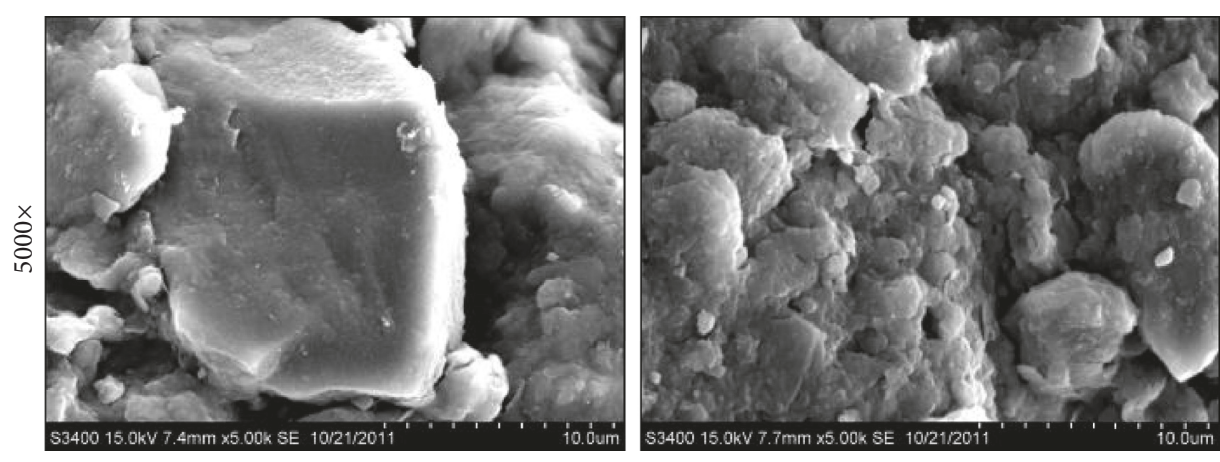

(c)

FIGURE 10: SEM micrographs of the samples with and without stabilization. Note: the SEM images were taken in 2011. 


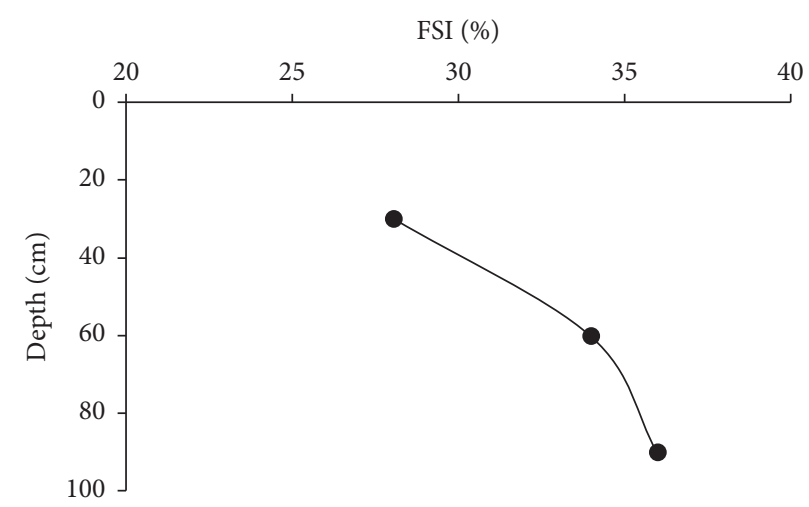

FIGURE 11: Free swell index at different depths.

OSI (\%)

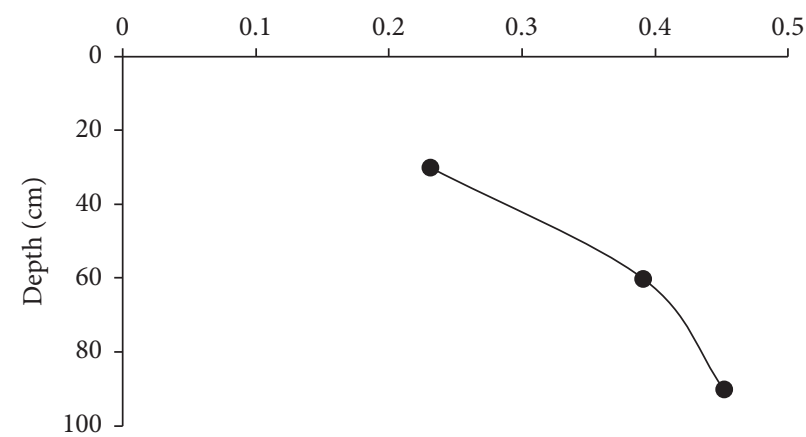

(a)

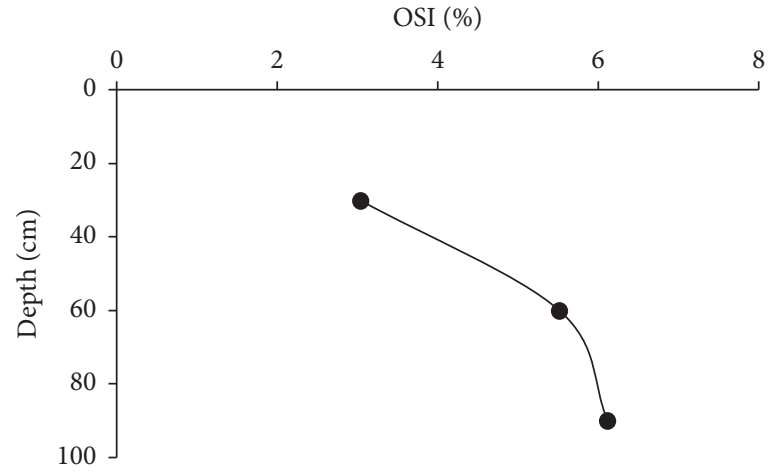

(b)

FIGURE 12: Oedometric swell index at different depths: (a) $50 \mathrm{kPa}$ loaded oedometric swell tests; (b) free oedometric swell tests.

3.6. Infiltration Test. One of the main goals of this work is to find a stabilizer which can be directly sprayed onto the soil surface and stabilize the natural expansive soil in the field simply by infiltration vertically through the small cracks and then horizontally into soil blocks. Then, the soil in the surface layer can be stabilized as a protection layer, and subsequently, it will help to resist drying-wetting cycles and rainfall events, keeping the moisture content constant in the deeper soil layer. Finally, the soil slope stability will be increased.

After spraying, the soil samples at the depths of $30 \mathrm{~cm}$, $60 \mathrm{~cm}$, and $90 \mathrm{~cm}$ were collected, and the free swell test results are shown in Figure 11. With the increase of depth, the FSI value was increasing, but even at the $90 \mathrm{~cm}$ depth, FSI was still smaller than $40 \%$, meaning that it fulfilled the requirement by the Chinese standard [28]. In addition, both loaded and free oedometric tests were performed, and the oedometric swell index values were calculated with equation (3) and shown in Figure 12. It shows that the OSI values were also increasing with the increase of soil depth, but the OSI values were always in a range which also met the field project requirements [28].

The shear strengths at the depths of $30 \mathrm{~cm}, 60 \mathrm{~cm}$, and $90 \mathrm{~cm}$ were also tested by direct shear tests with the vertical loads of $100 \mathrm{kPa}, 200 \mathrm{kPa}, 300 \mathrm{kPa}$, and $400 \mathrm{kPa}$. The test

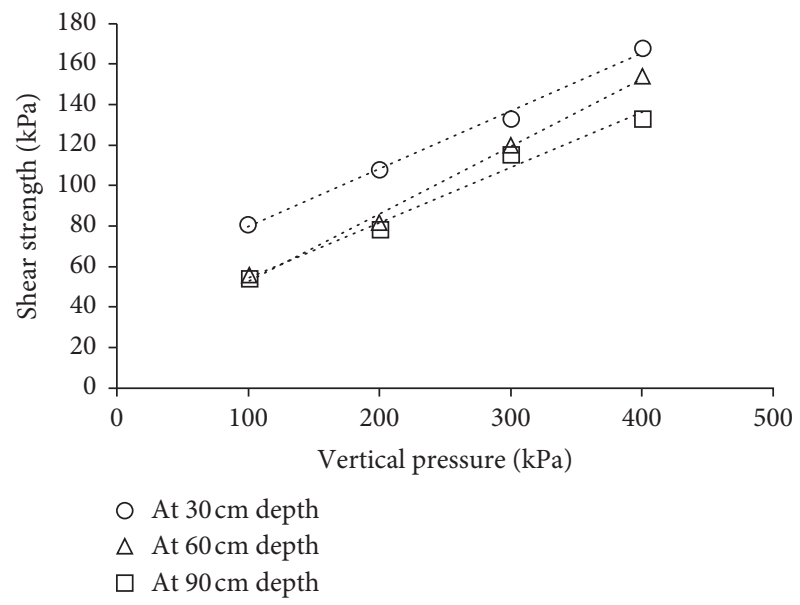

FIGURE 13: Shear strengths at different depths.

results are shown in Figure 13. It can be seen that higher vertical pressures induced higher shear strength values. However, it is more important that with the same amount of vertical pressure, the samples from deeper soil layers had smaller shear strength values, indicating more effective stabilization at the shallower soil layers. 


\section{Conclusions and Recommendations}

In this paper, polyvinyl alcohol and potassium carbonate were used to stabilize the expansive soil. Free swell tests, oedometric swell tests, unconfined compression tests, and direct shear tests were performed to study the swelling potential and shear strength of the stabilized soil. The microstructures of the stabilized soil were also studied with SEM photos. Finally, a laboratory model with a $1 \mathrm{~m}$ high soil column was built to simulate the stabilization of field soil by directly spraying the stabilizer solution onto the soil surface. Some conclusions can be summarized as follows:

(1) With the free swell test results, it shows that it is more effective to stabilize the expansive soil with the combination of PVA and $\mathrm{K}_{2} \mathrm{CO}_{3}$ than to do it with only PVA or $\mathrm{K}_{2} \mathrm{CO}_{3}$ individually.

(2) Oedometric test results confirmed the ability of the combination of PVA and $\mathrm{K}_{2} \mathrm{CO}_{3}$ to control the volume change. Unconfined compression test results showed that the stabilized soil samples had much higher strengths.

(3) After many drying-wetting cycles, the strength and volume changes of the stabilized soil samples were well controlled.

(4) SEM photos showed that the stabilized soil sample had more homogenous and denser microstructures than the natural expansive soil sample.

(5) The laboratory soil column model confirmed the ability of the stabilizer solution to form a thick protection layer to resist volume changes during drying-wetting cycles and keep the water content constant in the lower layer.

Finally, it can be concluded that the PVA and $\mathrm{K}_{2} \mathrm{CO}_{3}$ combination is able to serve as an effective stabilizer of expansive soil, and more importantly, it is possible to stabilize field soils by directly spraying the stabilizer solution on the soil surface, forming a thick protection layer.

\section{Data Availability}

The data used to support the findings of this study are included within the article.

\section{Conflicts of Interest}

The authors declare that they have no conflicts of interest.

\section{Acknowledgments}

This work was supported by the National Natural Science Foundation of China (NSFC no. 51778211) and the Natural Science Foundation of Jiangsu Province (Grant no. BK20171434).

\section{References}

[1] C. W. W. Ng, L. T. Zhan, C. G. Bao, D. G. Fredlund, and B. W. Gong, "Performance of an unsaturated expansive soil slope subjected to artificial rainfall infiltration," Géotechnique, vol. 53, no. 2, pp. 143-157, 2003.

[2] F. H. Chen, Foundations on expansive soils, Vol. 12, Elsevier, Amsterdam, Netherlands, 2012.

[3] F. Yazdandoust and S. S. Yasrobi, "Effect of cyclic wetting and drying on swelling behavior of polymer-stabilized expansive clays," Applied Clay Science, vol. 50, no. 4, pp. 461-468, 2010.

[4] P. K. Jayasree, K. Balan, L. Peter, and K. K. Nisha, "Volume change behavior of expansive soil stabilized with coir waste," Journal of Materials in Civil Engineering, vol. 27, no. 6, Article ID 04014195, 2014.

[5] L. C. Dang, B. Fatahi, and H. Khabbaz, "Behaviour of expansive soils stabilized with hydrated lime and bagasse fibres," Procedia Engineering, vol. 143, pp. 658-665, 2016.

[6] Y. X. Wang, P. P. Guo, W. X. Ren et al., "Laboratory investigation on strength characteristics of expansive soil treated with jute fiber reinforcement," International Journal of Geomechanics, vol. 17, no. 11, Article ID 04017101, 2017.

[7] A. Kumar, B. S. Walia, and A. Bajaj, "Influence of fly ash, lime, and polyester fibers on compaction and strength properties of expansive soil," Journal of Materials in Civil Engineering, vol. 19, no. 3, pp. 242-248, 2007.

[8] M. Mirzababaei, A. Arulrajah, S. Horpibulsuk, A. Soltani, and N. Khayat, "Stabilization of soft clay using short fibers and poly vinyl alcohol," Geotextiles and Geomembranes, vol. 46, no. 5, pp. 646-655, 2018.

[9] A. Soltani, A. Deng, and A. Taheri, "Swell-compression characteristics of a fiber-reinforced expansive soil," Geotextiles and Geomembranes, vol. 46, no. 2, pp. 183-189, 2018.

[10] M. Mirzababaei, M. Miraftab, M. Mohamed, and P. McMahon, "Impact of carpet waste fibre addition on swelling properties of compacted clays," Geotechnical and Geological Engineering, vol. 31, no. 1, pp. 173-182, 2013.

[11] M. Shahbazi, M. Rowshanzamir, S. M. Abtahi, and S. M. Hejazi, "Optimization of carpet waste fibers and steel slag particles to reinforce expansive soil using response surface methodology," Applied Clay Science, vol. 142, pp. 185-192, 2017.

[12] S. B. Ikizler, M. Aytekin, and M. Vekli, "Reductions in swelling pressure of expansive soil stabilized using EPS geofoam and sand," Geosynthetics International, vol. 16, no. 3, pp. 216-221, 2009.

[13] R. S. Sharma, B. R. Phanikumar, and B. V. Rao, "Engineering behavior of a remolded expansive clay blended with lime, calcium chloride, and rice-husk ash," Journal of Materials in Civil Engineering, vol. 20, no. 8, pp. 509-515, 2008.

[14] A. Al-Swaidani, I. Hammoud, and A. Meziab, "Effect of adding natural pozzolana on geotechnical properties of limestabilized clayey soil," Journal of Rock Mechanics and Geotechnical Engineering, vol. 8, no. 5, pp. 714-725, 2016.

[15] M. Abdelkrim and K. Mohamed, "Cement stabilization of compacted expansive clay," TOJSAT, vol. 3, no. 1, pp. 33-38, 2013.

[16] M. Khemissa and A. Mahamedi, "Cement and lime mixture stabilization of an expansive overconsolidated clay," Applied Clay Science, vol. 95, pp. 104-110, 2014.

[17] E. Çokça, "Use of class c fly ashes for the stabilizationof an expansive soil," Journal of Geotechnical and Geoenvironmental Engineering, vol. 127, no. 7, pp. 568-573, 2001.

[18] B. R. Kumar and R. S. Sharma, "Effect of fly ash on engineering properties of expansive soils," Journal of Geotechnical and Geoenvironmental Engineering, vol. 130, no. 7, pp. 764767, 2004.

[19] K. Punthutaecha, A. J. Puppala, S. K. Vanapalli, and $\mathrm{H}$. Inyang, "Volume change behaviors of expansive soils 
stabilized with recycled ashes and fibers," Journal of Materials in Civil Engineering, vol. 18, no. 2, pp. 295-306, 2006.

[20] E. Cokca, V. Yazici, and V. Ozaydin, "Stabilization of expansive clays using granulated blast furnace slag (GBFS) and GBFS-cement," Geotechnical and Geological Engineering, vol. 27, no. 4, pp. 489-499, 2009.

[21] H. Y. Poh, G. S. Ghataora, and N. Ghazireh, "Soil stabilization using basic oxygen steel slag fines," Journal of Materials in Civil Engineering, vol. 18, no. 2, pp. 229-240, 2006.

[22] A. Soltani, A. Deng, A. Taheri, and M. Mirzababaei, "A sulphonated oil for stabilisation of expansive soils," International Journal of Pavement Engineering, vol. 20, pp. 1-14, 2017.

[23] B. T. Wang, C. H. Zhang, X. L. Qiu, E. Y. Ji, and W. H. Zhang, "Research on wetting-drying cycles' effect on the physical and mechanical properties of expansive soil improved by OTAC$\mathrm{KCl}$," Advances in Materials Science and Engineering, vol. 2015, Article ID 304276, 7 pages, 2015.

[24] J. Q. Yu, R. L. Hu, H. M. Shang, F. P. Cui, and M. L. Yang, "Synergistic reaction of $\mathrm{K}^{+}$and polyvinyl alcohol on restraing swelling and hydrating behavior of expansive soil," Chinese Journal of Geotechnical Engineering, vol. 30, no. 6, pp. 900905, 2008.

[25] M. Al-Mukhtar, S. Khattab, and J.-F. Alcover, "Microstructure and geotechnical properties of lime-treated expansive clayey soil," Engineering Geology, vol. 139-140, pp. 17-27, 2012.

[26] S. Miao, Z Shen, X Wang et al., "Stabilization of highly expansive black cotton soils by means of geopolymerization," Journal of Materials in Civil Engineering, vol. 29, no. 10, Article ID 04017170, 2012.

[27] W. G. Holtz and H. J. Gibbs, "Engineering properties of expansive clays," Transactions of the American Society of Civil Engineers, vol. 121, pp. 641-677, 1956.

[28] GB 50112-2013, Technical Code for Buildings in Expansive Soil Regions, GB 50112-2013, Beijing, China, 2012.

[29] D. G. Fredlund and H. Rahardjo, Soil Mechanics for Unsaturated Soils, John Wiley \& Sons, Hoboken, NJ, USA, 1993. 


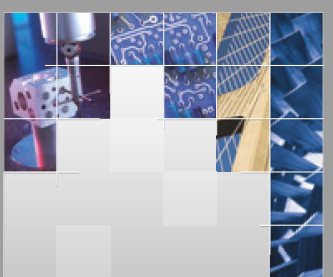

\section{Enfincering}
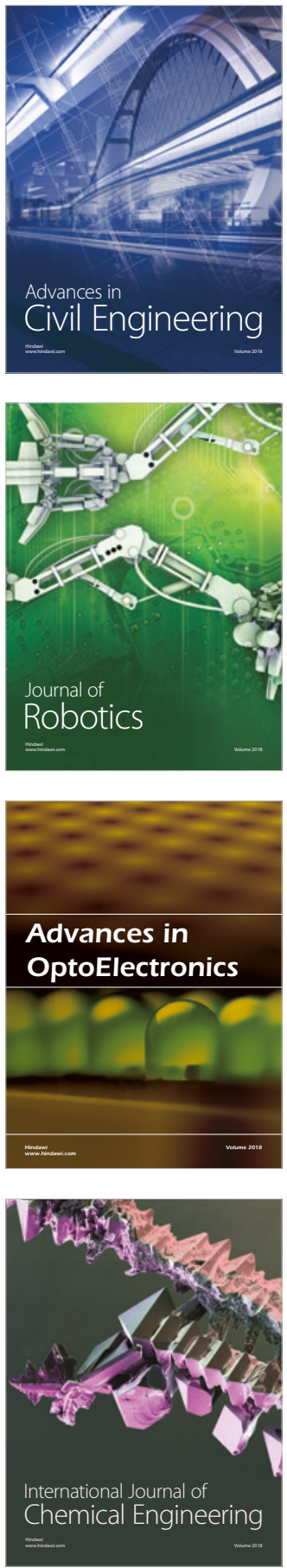

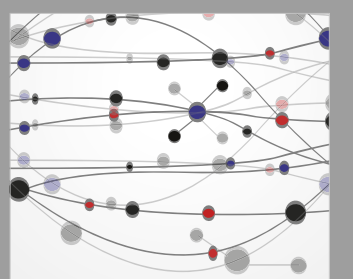

\section{Rotating \\ Machinery}

The Scientific World Journal

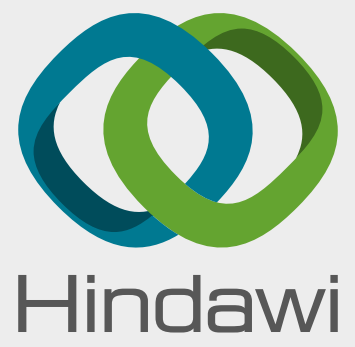

Submit your manuscripts at

www.hindawi.com
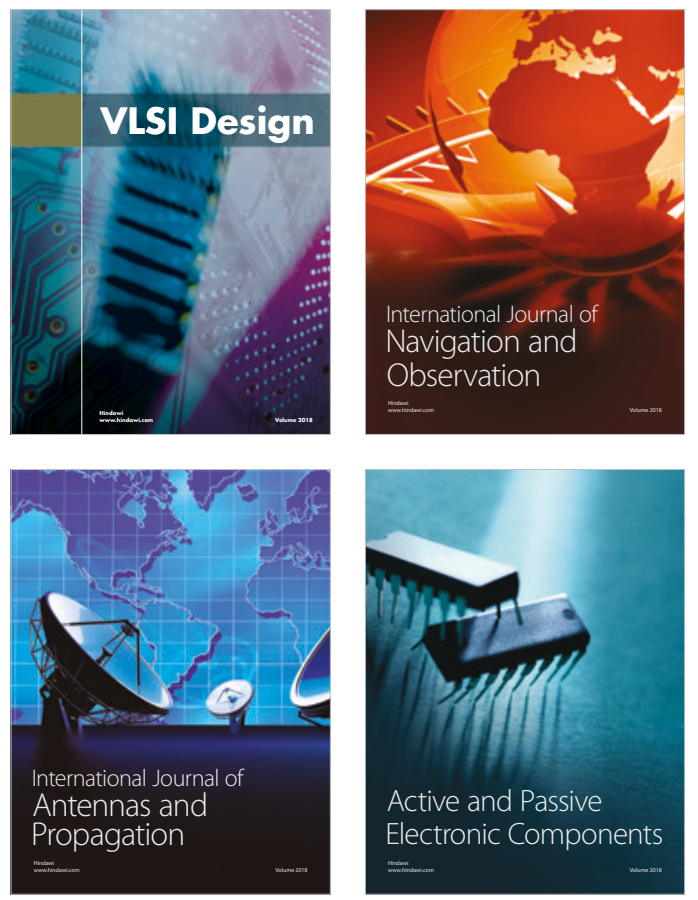
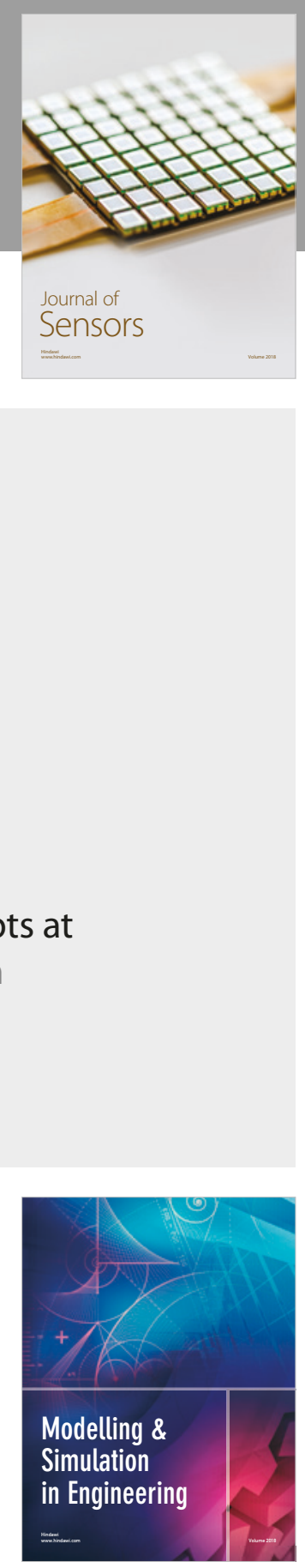

\section{Advances \\ Multimedia}
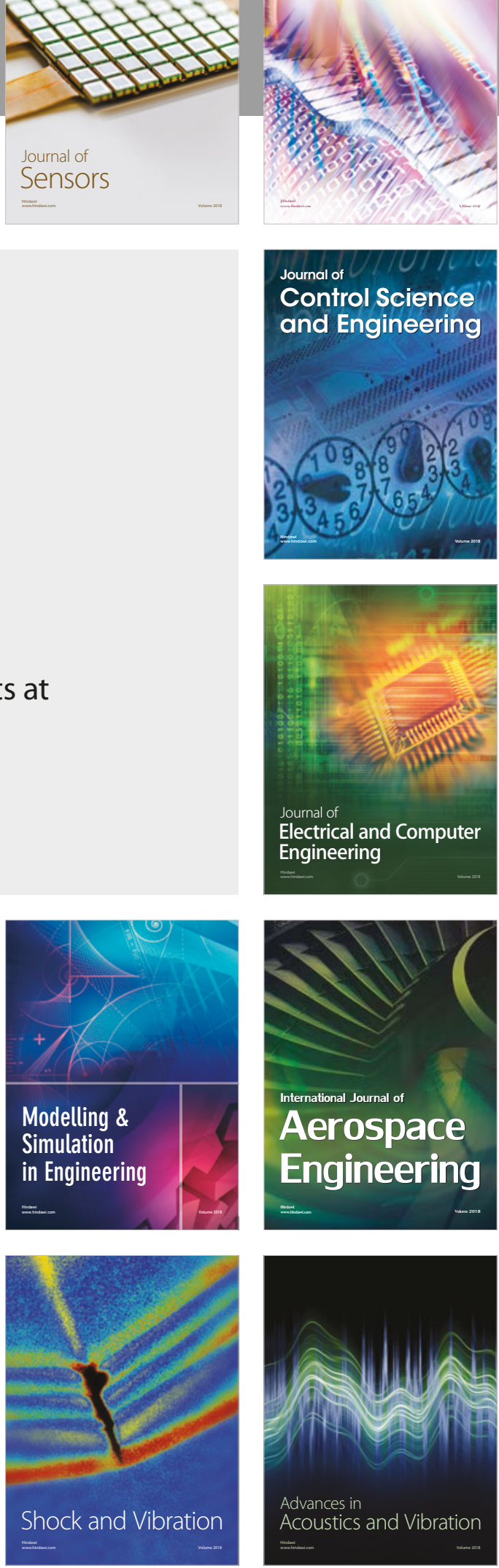